\title{
The Effect of Transfusion on Lung Capacity, Diffusing Capacity, and Arterial Oxygen Saturation in Patients with Thalassemia Major
}

\author{
GEORDIE P. GRANT, ${ }^{1}$ ANTHONY L. MANSELL, JOSEPH H. GRAZIANO, AND \\ ROBERT B. MELLINS \\ Departments of Pediatrics and Anesthesiology, Babies Hospital, College of Physicians and Surgeons of Columbia
}

University, New York, New York 10032

\begin{abstract}
Our previous cross-sectional study of patients with thalassemia major suggested progressive lung changes characterized by low total lung capacity, hypoxemia, and elevated transfer factor for carbon monoxide. We reevaluated nine of the patients for three reasons: 1 ) to determine the relationship of the previous findings to the immediate effects of blood transfusion; 2) to assess the longitudinal progression of the lung changes; and 3) to evaluate the effect of splenectomy on lung volume changes in these patients, all of whom underwent splenectomy in the interval between the two studies. We found that during the 5- to 6-yr period between studies total lung capacity had decreased significantly $(p<0.05)$ from a mean $86 \%$ predicted to a mean $79 \%$ predicted. However, vital capacity increased significantly $(p<0.05)$ from a mean $81 \%$ predicted to $88 \%$ with no significant change in functional residual capacity. There was no significant immediate effect of transfusion on total lung capacity, vital capacity, or functional residual capacity. However, the diffusion constant for carbon monoxide increased significantly $(p<$ $0.005)$ immediately following transfusion and there was a positive correlation between the increase and the amount of blood transfused $(r=0.74, p<0.05)$. Arterial oxygen saturation was below $95 \%$ in five of eight patients and increased significantly with transfusion $(p<0.05)$. We conclude: 1) thalassemia major and/or its treatment is associated with hypoxemia and a progressive reduction in total lung capacity. 2) Despite the progressive reduction in total lung capacity, splenectomy in patients with thalassemia major increases expiratory reserve volume and thereby increases vital capacity. 3) The previous finding of elevated $\mathbf{K}_{\mathrm{Co}}$ carbon monoxide is explained quantitatively as a transient effect caused by blood transfusion. 4) Transfusion in patients with thalassemia major without overt signs of cardiac failure is usually associated with a transient increase in arterial oxygen saturation. (Pediatr Res 20: 2023,1986 )
\end{abstract}

\section{Abbreviations}

$\mathrm{D}_{\mathrm{COsb}}$ or $\mathrm{DL}_{\mathrm{CO}}$, single breath diffusing capacity for carbon monoxide corrected for $\mathrm{Hb}$ concentration by the formula of Cotes et al. (6)

Received June 4, 1985; accepted August 14, 1985.

Correspondence and reprint requests, Dr. Anthony L. Mansell, Department of Pediatrics, Pulmonary Division, Babies Hospital South, Room 101, College of Physicians and Surgeons, Columbia University, 630 West 168 th Street, New York, NY 10032.

Supported in part by NHBLI Grant HL28986-01A1.

${ }^{1}$ Assistant Professor of Anesthesiology and Research Fellow in the Department of Pediatrics, Pulmonary Division.
$\mathrm{K}_{\mathrm{CO}}$, diffusion constant for carbon monoxide, or $\mathrm{DL}_{\mathrm{CO}}$ corrected for alveolar volume

VC, vital capacity

TLC, total lung capacity

TM, thalassemia major

In a previous study conducted in our laboratory (1), 17 patients with TM revealed a constellation of findings, including low lung volumes, increased maximum lung recoil, low static and dynamic compliance, elevated $\mathrm{K}_{\mathrm{co}}$, and hypoxemia. Because the previous study of pulmonary function was conducted immediately after transfusion, the major purpose of the present study was to separate the immediate effects of transfusion from the natural history or long-term progression of the disease. Thus we performed studies of pulmonary function before and immediately after transfusion in patients with TM.

Nine of the patients who participated in the first study were available for the current investigation. We thought it would be worthwhile retesting these patients for two reasons in addition to the question of transfusion effect. First, we evaluated the progression of lung changes found in the first study. Second, all the patients had undergone splenectomy since the previous study for improvement of iron balance. This circumstance provided an opportunity to examine the effect of splenectomy on lung volume.

\section{METHODS}

The study group consisted of nine thalassemic patients, ranging in age from 12-24 yr. All of the patients are either employed and/or attend school regularly. All the patients participated in the study conducted in our laboratory 6 yr previously (1). Thus we were able to compare lung volume changes based on predicted values for height in each patient. The patients were $90 \%$ of predicted mean height for age and sex both at the time of the first study and this study (2). Therefore, there was no significant change in growth percentile or percentage of mean for age. Six of the nine patients had significant growth retardation at the time of this study $(<2 \mathrm{SD})$. All have been receiving blood transfusions regularly (1-2 U every $2-4 \mathrm{wk}$ ) since the first year of life and subcutaneous deferoxamine-B for approximately $9 \mathrm{yr}$. All have hepatomegaly as they did in the first study but have undergone splenectomy during the interval between the two studies.

We performed each test prior to transfusion of the patient and repeated the study immediately after transfusion in eight of the patients. In one patient the posttransfusion testing was performed the morning following transfusion. 
Results from our laboratory for lung volumes in 54 subjects were similar to that of Polgar and Promadhat (3) and thus we used our values as normal reference standards for lung volumes. For the diffusing capacity $\left(\mathrm{D}_{\mathrm{COsb}}\right)$ and the diffusion constant for $\mathrm{K}_{\mathrm{CO}}$ we used published values from our laboratory (4) and for oxygen saturation we used data from a series of normal children ( $n=30)$ obtained in our laboratory.

Static lung volumes were obtained in each subject by standard spirometry using a 7-liter water filled spirometer. TLC was measured by the helium dilution technique.

The diffusing capacity diffusing capacity was obtained in each patient by the single breath technique (5). The values obtained were corrected for $\mathrm{Hb}$ concentration by the formula of Cotes et al. (6). The rate constant for $\mathrm{K}_{\mathrm{CO}}$ was calculated from the single breath measurement by correction for alveolar volume according to the equation of Krogh (7).

We used a Hewlett-Packard ear oximeter (HP-47201A) to obtain an estimate of arterial saturation. Measurements were made in the sitting position.

The two-tailed paired $t$ test was used to compare lung volume data obtained in the previous study (1) and the present study and to compare lung volume, saturation, and diffusing capacity data before and after transfusion in the present study (8). The relationship between two variables was assessed using linear regression analysis.

\section{RESULTS}

Lung volumes. Individual data for lung volumes before and after transfusion for the nine patients are given in Table 1. TLC measured by helium dilution was below the mean predicted for height in all the patients and below 2 SD in eight of the nine patients. The VC was below the mean predicted for height in all the patients and below 2 SD in three of the nine patients. Values for TLC, VC, and functional residual capacity did not change significantly after transfusion.

A comparison of TLC measurements immediately posttransfusion from the previous study (1) and those obtained in the present study is shown in Figure 1. Expressed in percent of predicted values according to height, TLC decreased significantly from a mean of $86 \pm 7$ (SD) to a mean of $79 \pm 7(p<0.05)$. The decrease in TLC was accomplished primarily by a reduction in residual volume from a mean percent predicted of $121 \pm 37$ to mean $46 \pm 11(p<0.001)$ and the residual volume/TLC ratio decreased from a mean of $0.29 \pm 0.07$ to a mean of $0.13 \pm 0.02$ $(p<0.001)$. Functional residual capacity increased slightly from a mean percent predicted of $75 \pm 13$ to $78 \pm 8$ and therefore did not change significantly between the two studies. As a result, VC actually increased from a mean percent predicted of $81 \pm 7$ to a mean of $88 \pm 6(p<0.05)$.
The mean value for forced expiratory volume in $1 \mathrm{~s}$ divided by VC was $0.87 \pm 0.06$ before transfusion and $0.85 \pm 0.04$ after transfusion; the difference was not significant.

Diffusing capacity. Individual measurements for $\mathrm{D}_{\text {cosb }}$ and $\mathrm{K}_{\mathrm{CO}}$ are listed for eight of the patients before and immediately after transfusion in Table 2 . These values were corrected for $\mathrm{Hb}$ obtained at the time of each study using the formula of Cotes et al. (6).

The mean value for $D_{\text {cosb }}$ was $12.1 \pm 2.50 \mathrm{ml} / \mathrm{min} / \mathrm{mm} \mathrm{Hg}$ before transfusion and $14.8 \pm 2.98$ after transfusion. Both the pre- and posttransfusion values were below the mean predicted for height (4) but the increase with transfusion was significant $(p<0.005)$.

The mean $\mathrm{K}_{\mathrm{CO}}$ was $4.84 \pm 0.61 \mathrm{ml} / \mathrm{min} / \mathrm{mm} \mathrm{Hg} /$ liter before transfusion and $6.27 \pm 1.23$ immediately after transfusion and the increase was significant $(p<0.005)$. The mean percent predicted $\mathrm{K}_{\mathrm{CO}}$ based on height (4) was $89 \pm 10$ before transfusion

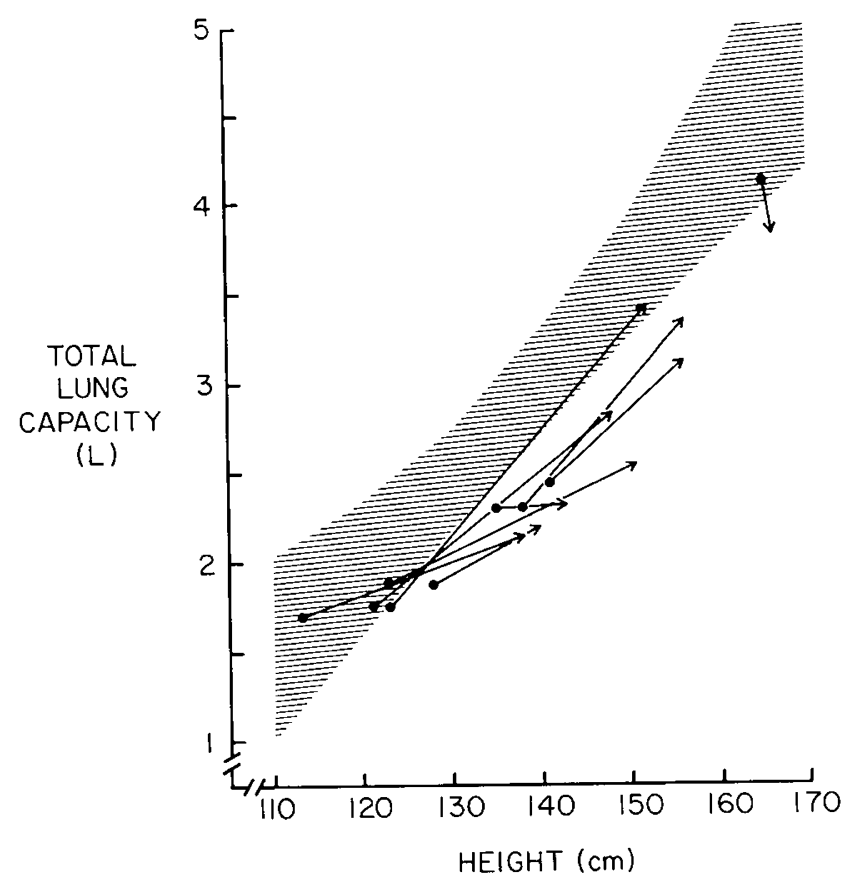

Fig. 1. A comparison of total lung capacity as a function of height between the previous study (1) and the present study in nine patients with TM. An individual patient is represented by a closed circle and an arrow. Shaded area represents \pm 2 SD of mean values for normal children, from Polgar and Promadhat (3).

Table 1. Summary of physical characteristics and lung volumes in nine patients with TM before and after transfusion

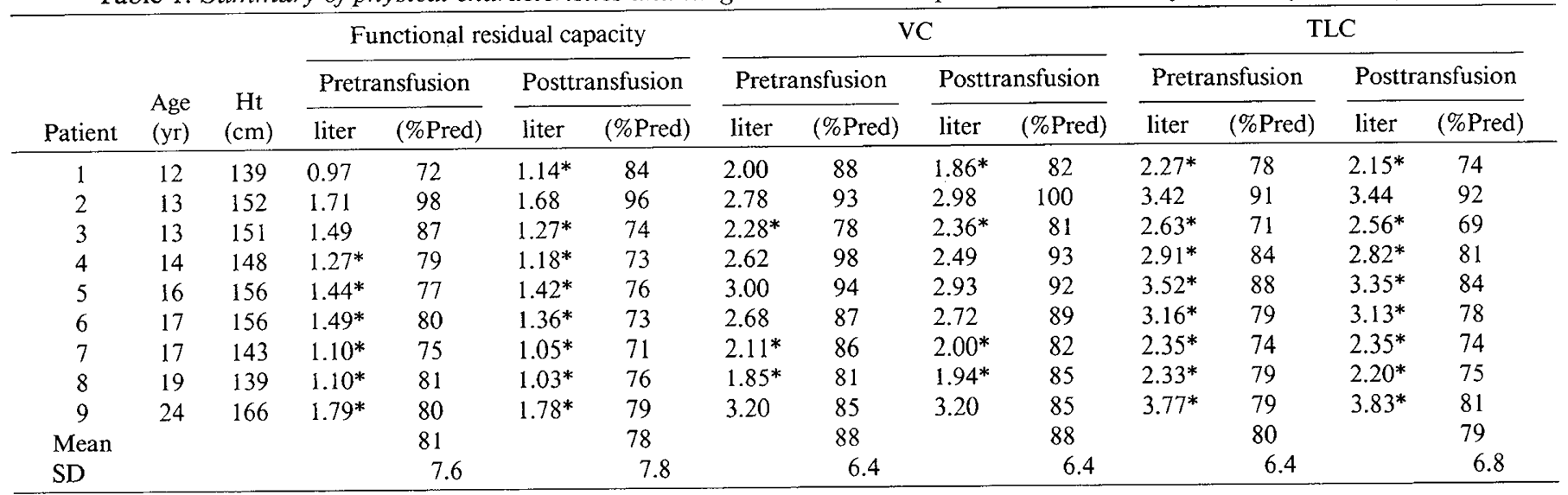

\footnotetext{
* Indicates values below $2 \mathrm{SD}$.
} 
Table 2. Summary of $H b$, oxygen saturation, and diffusing capacity in eight patients with TM before and immediately after transfusion

\begin{tabular}{|c|c|c|c|c|c|c|c|c|c|c|c|c|}
\hline \multirow[b]{3}{*}{ Patient } & & & & & \multicolumn{4}{|c|}{ DLco } & \multicolumn{4}{|c|}{$\mathrm{K}_{\mathrm{CO}}$} \\
\hline & \multicolumn{2}{|c|}{$\mathrm{Hb}(\mathrm{g} / \mathrm{dl})$} & \multicolumn{2}{|c|}{$\operatorname{Satn}^{*}(\%)$} & \multicolumn{2}{|c|}{ Pretransfusion } & \multicolumn{2}{|c|}{ Posttransfusion } & \multicolumn{2}{|c|}{ Pretransfusion } & \multicolumn{2}{|c|}{ Posttransfusion } \\
\hline & Pre & Post & Pre & Post & $\begin{array}{c}(\mathrm{ml} / \mathrm{min} / \\
\mathrm{mm} \mathrm{Hg})\end{array}$ & (\%Pred) & $\begin{array}{c}(\mathrm{ml} / \mathrm{min} / \\
\mathrm{mm} \mathrm{Hg})\end{array}$ & (\%Pred) & $\begin{array}{c}(\mathrm{ml} / \mathrm{min} / \\
\mathrm{mm} \mathrm{Hg} / \text { liter })\end{array}$ & $(\%$ Pred $)$ & $\begin{array}{c}(\mathrm{ml} / \mathrm{min} / \\
\mathrm{mm} \mathrm{Hg} / \text { liter })\end{array}$ & (\%Pred) \\
\hline 1 & 11.0 & 14.7 & $92 \dagger$ & $94 \dagger$ & 10.8 & 65 & 15.3 & 93 & 5.40 & 94 & 8.40 & 147 \\
\hline 3 & 13.7 & 14.0 & $93 \dagger$ & 95 & 10.9 & 51 & 15.6 & 79 & 4.66 & 87 & 5.85 & 109 \\
\hline 4 & 10.9 & 12.7 & $92 \dagger$ & 96 & 9.7 & 51 & 15.0 & 79 & 4.10 & 75 & 6.47 & 118 \\
\hline 5 & 11.1 & 13.0 & 95 & 96 & 17.6 & 82 & 21.5 & 100 & 5.70 & 109 & 7.04 & 134 \\
\hline 6 & 12.3 & 11.1 & $91 \dagger$ & $91 \dagger$ & 13.3 & 62 & 15.5 & 72 & 4.89 & 93 & 5.91 & 113 \\
\hline 7 & 13.1 & 12.4 & 96 & 95 & 9.4 & 53 & 11.8 & 67 & 4.78 & 85 & 5.83 & 104 \\
\hline 8 & 11.5 & 13.9 & 95 & 97 & 11.6 & 70 & 13.5 & 81 & 5.25 & 92 & 6.55 & 115 \\
\hline 9 & 12.0 & 12.7 & $91 \dagger$ & 95 & 13.4 & 54 & 13.8 & 55 & 3.96 & 80 & 4.07 & 82 \\
\hline Mean & 12.0 & 13.1 & 93 & $95 \ddagger$ & 12.1 & 61 & $14.8 \S$ & $78 \S$ & 4.84 & 89 & $6.27 \S$ & $115 \S$ \\
\hline $\mathrm{SD}$ & & & 2.0 & 1.8 & 2.50 & 11 & 2.98 & 14 & .61 & 10 & $1.23^{\circ}$ & $19^{\circ}$ \\
\hline
\end{tabular}

* The percent of $\mathrm{Hb}$ saturated by oxygen measured by ear oximetry.

$\dagger$ Indicates values $94 \%$ or below, considered abnormally low compared to normal controls from our laboratory.

$\ddagger$ Indicates significant increase with transfusion, $p<0.05$.

$\S$ Indicates significant increase with transfusion, $p<0.005$.

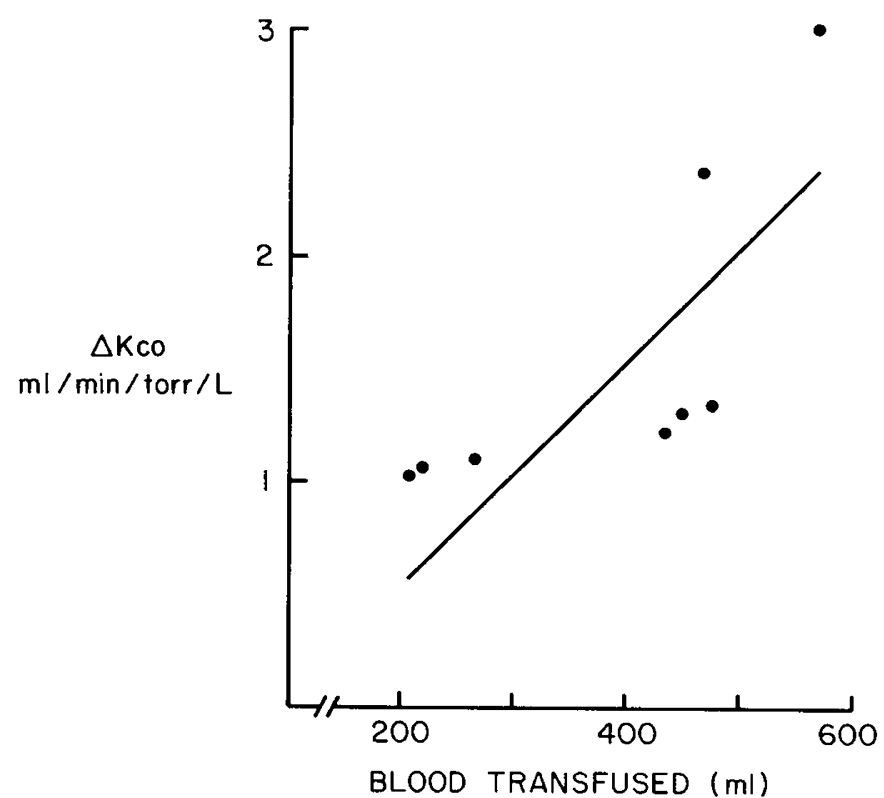

Fig. 2. The change in the diffusion constant for $\mathrm{K}_{\mathrm{CO}}$ as a function of the quantity of blood transfused in eight patients with TM. The straight line represents linear regression analysis $(r=0.74, p<0.05)$.

and increased significantly to a mean of $115 \pm 19$ with transfusion $(p<0.005)$.

We also looked at the relationship of the amount of blood transfused (ml of packed cells) to $\Delta \mathrm{K}_{\mathrm{CO}}$ (Fig. 2). There was a significant correlation between $\Delta \mathrm{K}_{\mathrm{CO}}$ and the amount of blood transfused using linear regression analysis $(r=0.74, p<0.05)$. Because the $\mathrm{K}_{\mathrm{CO}}$ was related to the amount of blood transfused, we did not compare posttransfusion diffusing capacity values obtained in the previous study to those obtained in the present study.

Arterial saturation. Individual measurements of $\mathrm{Hb}$ oxygen saturation by ear oximetry in the sitting position for eight patients before and immediately after transfusion are listed in Table 2. These values were abnormally low in five of the patients compared to the normal controls from our laboratory $(n=30)$ but there was a significant increase in saturation with transfusion $(p<0.05)$ and the values were abnormal in only two of the patients after transfusion.

\section{DISCUSSION}

Large, rapid transfusions of blood have been shown to diminish vital capacity in subjects who were normovolemic before transfusion (9). Evidence for a decrease in lung gas volume associated with pulmonary vascular engorgement was suggested by Gray et al. (10). Our data show no significant immediate effect of transfusion on total TLC and its subdivisions in the patients with TM. This may be related to the fact that the blood was given slowly $(<3 \mathrm{ml} / \mathrm{kg} / \mathrm{h})$ and the amount $(10 \mathrm{ml}$ of filtered, washed, packed red cells $/ \mathrm{kg}$ ) (11) was not sufficient to produce the increase in pulmonary blood volume necessary to affect thoracic gas volume. We conclude that the reduction of TLC detected in patients with TM is not a transient effect of transfusion.

The elevated diffusion constant for $\mathrm{K}_{\mathrm{CO}}$ is a transient effect of transfusion. Furthermore, our results show a significant positive correlation between the increase in $\mathrm{K}_{\mathrm{co}}$ and the amount of blood transfused. This correlation would not be caused by a higher rate of $K_{c o}$ uptake by the transfused red cells because the values for $\mathrm{K}_{\mathrm{CO}}$ were corrected for $\mathrm{Hb}$ content (6) and because chronic transfusion in these patients markedly diminishes erythropoiesis, yielding a virtually normal $\mathrm{Hb}$ type $(\mathrm{Hb} \mathrm{A})$, which is maintained throughout the interval between transfusions (12). A likely explanation for the increase in $\mathrm{K}_{\mathrm{CO}}$ is an increase in pulmonary capillary blood volume (13). This may be associated with a more uniform interregional distribution of pulmonary capillary volume after transfusion in a manner similar to that which has been shown to occur with a change from the upright to the supine posutre $(4,14,15)$. In addition, Daly et al. (14) showed an increase in pulmonary diffusing capacity associated with use of an inflation suit which forced a shift in blood volume to the lungs.

The cause for hypoxemia detected in our previous study and confirmed by Keens et al. (16) has not been identified. We considered the possibility that it was a transient effect of transfusion. A mechanism for a decrease in arterial $\mathrm{po}_{2}$ after transfusion was suggested in studies by Barrett et al. $(17,18)$, who showed an increase in pulmonary shunting following large blood transfusions and proposed embolization of microaggregates to the pulmonary circulation as the major mechanism. They also 
concluded that this deleterious effect on gas exchange could be prevented by filtering of the blood. A second mechanism causing hypoxemia could be development of interstitial lung edema from pulmonary vascular engorgement. However, we found that arterial oxygen saturation tended to be low before transfusion and increased immediately after transfusion. We considered several mechanisms to explain the increase in saturation with transfusion. One possibility is the improved top to bottom distribution of perfusion as occurs with postural changes in normal individuals $(19,20)$. This would only apply to our patients if their hypoxemia were caused by an exaggerated top to bottom interregional mismatch of ventilation and perfusion. There is no reason to believe this would occur. A second possibility is hyperventilation related to the transfusion. Although we had no reason to believe that this did occur, we cannot rule out hyperventilation because we did not measure arterial $\mathrm{pCO}_{2}$. A third explanation is an increase in mixed venous $\mathrm{pO}_{2}$ in the presence of venous admixture. As shown by Kelman et al. (21), cardiac output and mixed venous oxygen content change in the same direction for a given oxygen consumption. Therefore, in the presence of a constant venous admixture and oxygen consumption, an increase in cardiac output should lead to an increase in arterial oxygen content because the blood passing through the areas of venous admixture has a higher oxygen content. Venous admixture includes true anatomical shunt and ventilation/perfusion abnormalities. This mechanism, however, presumes an increase in cardiac output with transfusion; we did not study this.

Over the 5- to 6-yr period between this and our previous study, TLC did not increase in proportion with body growth. This longitudinal finding is consistent with cross sectional data from the original study, which showed that reduction in TLC was most prominent in the oldest patients. Despite the progressive restriction on expansion of the lungs, which our previous study showed to be associated with excessive lung recoil at TLC, VC actually increased significantly. This increase in VC is not consistent with the concentric reduction in subdivisions of TLC usually associated with restrictive lung disease. Because all of the patients had undergone splenectomy and because expiratory reserve volume increased in all, the enlarged spleens may have limited emptying of the lungs during forced expiratory maneuvers in the earlier study. However, we have no measurements of chest wall recoil before or after splenectomy in these patients. Therefore we do not know the mechanism associating splenectomy with the increase in VC.

In summary, the present study confirms that there is a progressive pulmonary impairment from TM and/or its treatment. In the previous study this impairment was characterized by reduction in TLC and lung compliance, excessive inward recoil of the lungs at full expansion and arterial hypoxemia. The pathophysiologic basis for the pulmonary impairment remains unclear. Splenectomy is associated with an increase in expiratory reserve volume, decreasing the effect of progressive lung changes on VC. In addition, splenectomy has reduced the amount of transfused blood required to maintain the desired $\mathrm{Hb}$ of $11.5 \mathrm{~g} /$ dl (11). Transfusion produces a transient improvement in arterial hypoxemia and a transient elevation of the $\mathrm{K}_{\mathrm{co}}$ ( $\mathrm{Hb}$ corrected) in these patients. Despite the highly specialized treatment regimen, including maintenance of the $\mathrm{Hb}$ level within a narrow range, deferoxamine- $B$ treatment, use of specially filtered and processed blood products and splenectomy (11), patients with
TM continue to experience rapid clinical deterioration in their third decade, at a later age than the patients evaluated in this study. At that stage, how much the pulmonary impairment has progressed and to what extent it contributes to the deterioration remains unclear.

Acknowledgments. The authors thank Dr. Sergio Piomelli for his cooperation and referral of patients under his care and to Mrs. Ruth Kessler and Mr. Robert Garofano for their technical assistance in the Pulmonary Function Laboratory.

\section{REFERENCES}

1. Cooper DM, Mansell AL, Weiner MA, Berdon WE, Chetty-Baktaviziam A, Reid L, Mellins RB 1980 Low lung capacity and hypoxemia in children with thalassemia major. Am Rev Respir Dis 121:639-646

2. Vaughan VC, McKay RJ, Nelson WE 1975 Growth and development. In: Nelson Textbook of Pediatrics, 10th ed. WB Saunders, Philadelphia, pp 4245

3. Polgar G, Promadhat V 1971 Standard values. In: Pulmonary Function Testing in Children. WB Saunders, Philadelphia, pp 126-135

4. O'Brodovich HM, Mellins RB, Mansell AL 1982 Effects of growth on the diffusion constant for carbon monoxide. Am Rev Respir Dis 125:670-673

5. Ogilve CM, Forster RE, Blakemore WS, Morton JW 1957 A standardized breath holding technique for the clinical measurement of the diffusing capacity of the lung for carbon monoxide. J Clin Invest 26:1-17

6. Cotes JE, Dabbs JM, Elwood PC, Hall AM, McDonald A, Saunders M 1972 Iron deficiency: its effect on transfer factor. Clin Sci 42:325-335

7. Krogh M 1914 The diffusion of gases through the lungs of man. J Physiol (Lond) 49:271-300

8. Zar JH 1974 Paired-sample hypotheses. In: Biostatistical Analysis. PrenticeHall, Inc., Englewood Cliffs, NJ, pp 121-122

9. Mollison PL 1983 The transfusion of red cells. In: Blood Transfusion in Clinical Medicine, 7 th ed. Blackwell Scientific Publications, Oxford, pp $124-130$

10. Gray BA, McCaffree DR, Sivak ED, McCurdy HT 1978 Effect of pulmonary vascular engorgement on respiratory mechanics in the dog. $J$ Appl Physiol 45:119-127

11. Piomelli S, Hart D, Graziano J, Grant G, Karpatkin M, McCarthy K 1985 Current strategies in the management of Cooley's anemia. Ann NY Acad Sci 445:256-267

12. Correra A, Graziano JH, Seaman C, Piomelli S 1984 Inappropriately low red cell 2,3-diphosphoglycerate and p50 in transfused B-thalassemia. Blood 63:803-806

13. Roughton FJW, Forster RE 1957 Relative importance of diffusion and chemical reaction rates in determining rate of exchange of gases in the human lung, with special reference to true diffusing capacity of pulmonary membrane and volume of blood in the lung capillaries. J Appl Physiol 11:290302

14. Daly WJ, Giammona ST, Ross JC, Feigenbaum H 1964 Effects of pulmonary vascular congestion on postural changes in the perfusion and filling of the pulmonary vascular bed. J Clin Invest 43:68-76

15. Giammona STH, Daly WJ 1965 Pulmonary diffusing capacity in normal children, ages 4 to 13. Am J Dis Child 110:144-151

16. Keens TG, O’Neal MH, Ortega JA, Hyman CB, Platzker ACG 1980 Pulmonary function abnormalities in thalassemia patients on a hypertransfusion program. Pediatrics 65:1013-1017

17. Barrett J, Tahir AH, Litwin MS 1978 Increased pulmonary arteriovenous shunting in humans following blood transfusion. Arch Surg 113:947-950

18. Barrett J, Dawidson T, Dhurandhar HN, Miller E, Litwin MS 1975 Pulmonary microembolism associated with massive transfusion: II. The basic pathophysiology of its pulmonary effects. Ann Surg 182:56-61

19. Glaister DH 1967 The effect of posture on the distribution of ventilation and blood flow in the normal lung. Clin Sci 33:391-398

20. Kaneko K, Milic-Emili J, Dolovich MB, Dawson A, Bates DV 1966 Regional distribution of ventilation and perfusion as a function of body position. $J$ Appl Physiol 21:767-777

21. Kelman GR, Nunn JF, Prys-Roberts C, Greenbaum R 1967 The influence of cardiac output on arterial oxygenation: a theoretical study. $\mathrm{Br} \mathrm{J}$ Anaesth $39: 450-458$ 